\title{
EFEITO DO 2,4-D NA INDUÇÃO DE CALOS EM Amburana cearensis(ALLEMÃO)
}

\section{A. C. SMITH.}

\section{DINAH ISE J. G. E C. PINTO ${ }^{1}$;JÉSSICA NASCIMENTO COSTA VASCONCELOS'; ALONE LIMA BRITO; ;JOSÉ RANIERE FERREIRA DE SANTANA $^{4}$}

1.Bolsista Fapesb, Granduanda em Agronomia, Universidade Estadual de Feira de Santana, e-mail: dinahagro@hotmail.com

2.Doutoranda em Biotecnologia, Universidade Estadual de Feira de Santana; e-mail: jejesmile@ hotmail.com

3. Professora, DCBIO, Universidade Estadual de Feira de Santana; e-mail: lima_brito@yahoo.com.br

4. Orientador, DCBIO, Universidade Estadual de Feira de Santana; e-mail: raniere@uefs.br

PALAVRAS-CHAVE:calogênese; auxina; cumaru.

\section{INTRODUÇÃO}

Amburana cearenses (ALLEMÃO) A. C. SMITH., conhecida popularmente como "cumaru" ou "umburana-de-cheiro", é uma planta arbórea da família das Leguminoseae (Fabaceae), e subfamília Papilionoideae amplamente distribuída no Nordeste brasileiro. Sua madeira é utilizada na movelaria, e a casca bem como as sementes são utilizadas para fins medicinais, devido a sua atividade antiinflamatória, analgésica, antiespasmódica e broncodilatadora (LORENZI, 1992; ALMEIDA et al., 2010).

O sucesso das pesquisas químicas e farmacológicas de A. cearensis estimulou a produção de seus fitoterápicos em escala industrial. Porém, considerando que a maioria das plantas medicinais é explorada de maneira predatória e indiscriminada e que a indústria farmacêutica precisa de matéria prima homogênea e em larga escala, é necessária a utilização de sistemas de cultivo que possibilitem a obtenção de um grande número de plantas em tempo reduzido e permitam a conservação e exploração racional e sustentável das espécies.

Neste contexto, as técnicas de cultura de tecidos possibilitam a produção de um grande número de plantas a partir de um único indivíduo, podendo ser utilizada para a conservação e propagação dessa espécie em escala comercial. A micropropagação tem se mostrado uma alternativa viável para a conservação e reprodução de espécies nativas com risco de extinção. Tal técnica consiste basicamente em cultivar em ambiente asséptico, com temperatura e iluminação controlada, qualquer parte da planta, em meio nutritivo adequado; e pode ser feita por dois processos distintos: organogênese e embriogênese (GRATTAPAGLIA; MACHADO, 1998).

A organogênese é o processo de neoformação de parte aérea ou raiz a partir de tecidos da planta.Já a embriogênese somática consiste no desenvolvimento de embriões a partir de células somáticas embriologicamente competentes in vitro. Ambos os processos podem ocorrer pela via direta ou indireta, quando há a necessidade de desdiferenciação do explante, com a consequente formação de uma fase intermediária de calo antes do estabelecimento das células competentes (BERTOZZO; MACHADO, 2010; AHUJA, 1992). A embriogênese somática indireta é considerada uma das formas mais adequadas para a multiplicação in vitro, pois possibilita elevada taxa de multiplicação, sendo a indução de calos embriogênicos uma das etapas mais importantes deste processo de regeneração de brotos.

Assim, o presente trabalho visa avaliar o efeito do 2,4-D na indução de calos em umburana-de-cheiro (Amburana cearensis).

\section{MATERIAL E MÉTODOS}

\section{Local de realização do experimento}

Os experimentos foram conduzidos no Laboratório de Cultura de Tecidos Vegetais (LCTV), pertencente a Unidade Experimental Horto Florestal/UEFS. 


\section{Material Vegetal}

Para obtenção de plantas in vitro, sementes de amburana foram lavadas em água corrente por 10 minutos, em seguida desinfestadas em câmara de fluxo laminar com imersão em etanol a $70 \%$ por 1 minuto e posteriormente em solução de hipoclorito de sódio - $\mathrm{NaOCl}$ [água sanitária comercial (Qboa $®)$ - 2,5\% de cloro ativo] com 2 gotas de detergente neutro (Ypê $\left.{ }^{\circledR}\right)$ por 10 minutos.Após esse período, as sementes foram lavadas quatro vezes com água destilada estéril e inoculadas em tubos contendo $15 \mathrm{~mL}$ de meio de cultura, conforme metodologia estabelecida por Campos (2009).

\section{Efeito do 2,4-diclorofenoxiacético (2,4-D) na indução de calos em diferentes tipos de explantes de $A$. cearensis.}

O meio de cultura utilizado foi o WPM (Wood PlantMedium), suplementado com 3\% de sacarose (Synth ${ }^{\circledR}$ ) e solidificado com 0,7\% de Agar (Himedia ${ }^{\circledR}$ ). $\mathrm{O}$ pH do meio de cultura foi aferido para 5,7 \pm 01 com hidróxido de sódio $(\mathrm{NaOH})$ ou ácido clorídrico $(\mathrm{HCl})$ a $0,1 \mathrm{~N}$ antes da autoclavagem, que foi realizada a temperatura de $121^{\circ} \mathrm{C}$ e pressão de $1 \mathrm{~atm}$ por 15 minutos.

Os explantes(segmentos cotiledonares e foliares), oriundos de plântulas germinadas in vitro com 45 dias de idade, foram inoculados em tubos de ensaio contendo $15 \mathrm{~mL}$ de meio de cultura, suplementado com diferentes concentrações de 2,4-D $(0,0 ; 5,0 ; 10,0 ; 20,0 ; 40,0 \mu \mathrm{M})$.

O delineamento estatístico foi o inteiramente casualizado, em esquema fatorial $2 \times 5$, totalizando 10 tratamentos com cinco repetições por tratamento, sendo cada repetição composta por quatro tubos de ensaio. Após 30 dias foram avaliados: percentual de explantes responsivos (ER\%), percentual da área do explante coberta por calos (AC\%), coloração e textura dos calos.

\section{Condições de cultivo}

Os experimentos in vitro foram mantidos em sala de crescimento, com temperatura de $26 \pm 2^{\circ} \mathrm{C}$, fotoperíodo de $16 \mathrm{~h}$ e radiação fotossintética ativa de $60 \mu \mathrm{mol} \mathrm{m} \mathrm{m}^{-2} \mathrm{~s}^{-1}$ obtida através de lâmpadas brancas fluorescentes.

\section{Analise Estatística}

Os dados foram avaliados estatisticamente, mediante a análise de variância, testandose as médias pelo Teste de Tukey para os fatores qualitativos, e ajustes de equação de regressão polinomial para os quantitativos usando o programa SISVAR, desenvolvido pela UFLA (FERREIRA, 2011).

\section{RESULTADOS E DISCUSSÃO}

A análise de variância indicou efeitos significativos $(\mathrm{p}<0,05)$ da interação entre o 2,4-D (D) e o tipo de explante (E) sobre a indução de calos de A. cearensisnas variáveis analisadas.

Com relação ao percentual de explantes responsivos em segmentos foliares e cotiledonares, a análise de regressão apontou um modelo quadrático ascendente $(\mathrm{p}<0,05)$ para o efeito do 2,4-D na indução de calos (Figura 1).Para os segmentos foliares constatouse que ao aumentar a concentração de 2,4-D houve aumento do percentual de explantes responsivos até atingir a concentração máxima de $21,94 \mu \mathrm{M}$ com $99,42 \%$ de explantes com calos. Já considerando o percentual de explantes responsivos em segmentos cotiledonares, observa-se que o percentual máximo $(99,38)$ de calos formados é obtido com o uso de 26,46 $\mu \mathrm{M}$ de 2,4-D (Figura1).

O 2,4-D é a auxina mais empregada nos processos de calogênese. Tal uso está relacionado com o papel deste regulador de crescimento vegetal na célula, pois ele estimula 
o início da divisão e atua controlando o crescimento celular através do aumento na produção de RNA polimerase, estimulando a produção de RNA e biossíntese de diversas proteínas de crescimento (GEORGE, 1996; OLIVEIRA, 2011). Assim, sob ação do 2,4-D, as células do explante passam pelo processo de desdiferenciação, seguido de divisão (GEORGE et al., 2008).

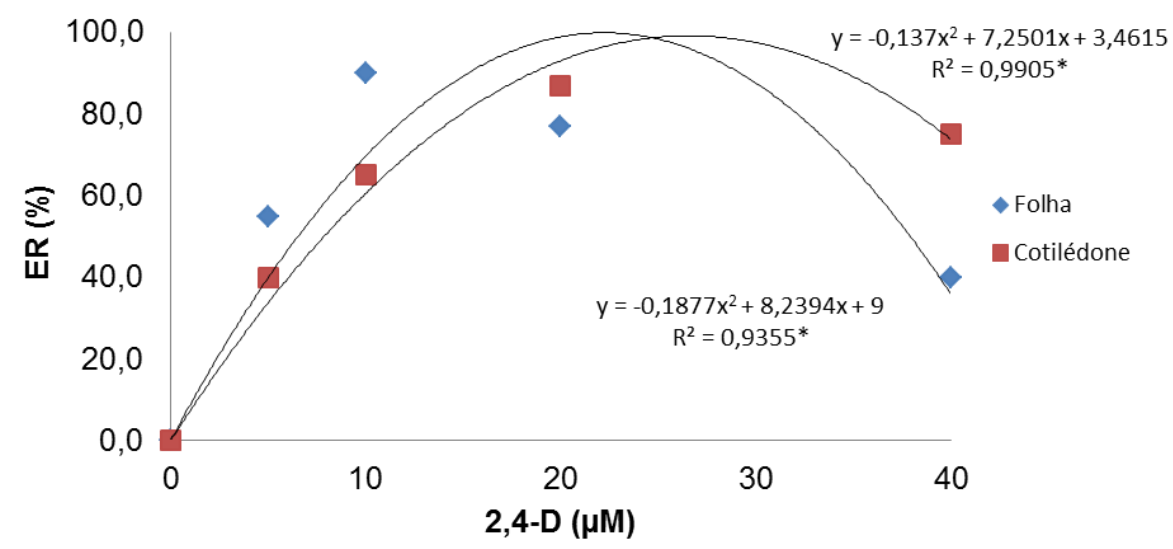

Figura 1 - Porcentagem de explantes responsivos (ER\%) de A. cearensis, submetidos a diferentes concentrações de 2,4-D. *Significativo ao nível de $5 \%$ de probabilidade pelo teste F. Feira de Santana, 2016.

No presente trabalho, a adição de 2,4-D ao meio de cultura foi essencial na indução de calos visto que os explantes cultivados sem a adição de regulador de crescimento oxidaram. Efeitos similares foram relatados por Rahim et al. (2003) em explantes de Eucalyptuscamaldulensisquando inoculados em meio de cultura livre de 2,4-D. Desse mesmo modo, Werner et al. (2007) comprovaram que os folíolos de Caesalpiniaechinata são totalmente dependentes da presença do regulador de crescimento 2,4-D para a indução de calos.

Entretanto, resultado contrário foi observado por Reis et al. (2007) ao estudar a indução de calos em paricá (Schizolobiumparahyba var. amazonicum), no qual mesmo sem a presença de regulador vegetal ocorreu a calogênese.

$\mathrm{Na}$ presente pesquisa observa-se que os melhores percentuais de calogênese foram obtidos nas concentrações de $21,94 \mu \mathrm{M}$ e $26,46 \mu \mathrm{M}$ para explantes foliares e cotiledonares, respectivamente. Porém, Sado (2009) relatou o maior potencial de explantes responsivos $(73,4 \%)$ quando cotilédones de Senna spectabilis foram cultivados na concentração de 11,32 $\mu \mathrm{M}$ de 2,4-D. Já Vasconcelos et al. (2012) constatou que o percentual de calos em explantes foliares de Myracrodruonurundeuva ocorreu nas concentrações de 4,52 e 6,78 $\mu \mathrm{M}$ de 2,4-D.

$\mathrm{O}$ efeito do 2,4-D na indução de calos é bastante citado na literatura, porém não existe um padrão de qual concentração é mais eficiente. Este efeito é influenciado pela espécie, pelo genótipo e pelo explante, o que justifica o estabelecimento de protocolos específicos (INÁCIO, 2010).

Os explantes utilizados neste trabalho, folha e cotilédone, apresentaram alto potencial calogênico, com valores máximos de $99,42 \%$ e $99,38 \%$, respectivamente.Segundo Grattapaglia \& Machado (1998) e Handro \&Floh (1990), qualquer parte da planta pode ser utilizada como explante, contudo, é indicado o uso de tecidos e órgãos contendo células não diferenciadas, com maior capacidade para expressar a totipotência e apresentando maiores proporções de tecido meristemático e menores quantidade de lignina.

A eficiência dos explantes empregados neste estudo é evidenciada por Venturiere \& Venturiere (2004) e Vasconcelos (2012). Enquanto Venturiere\& Venturiere (2004) 
averiguaram a maior frequência de calogênese no hibrido Theobromagrandiflorum $\mathrm{x}$ Theobromaobovatum usando o cotilédone como fonte de explante; Vasconcelos (2012) destaca a utilização de explantes foliares na indução de calos em aroeira-do-sertão (Myracrodruonurundeuva).

A análise de regressão apontou um modelo quadrático ascendente $(\mathrm{p}<0,01)$ para a porcentagem de área do explante foliar e cotiledonar recoberta por calos (Figura 2). Após trinta dias de cultivo, houve formação calos sobre a superfície dos explantes em todas as concentrações testadas, exceto no meio de cultura isento de regulador vegetal. O percentual máximo de área foliar contendo calos $(86,37 \%)$ é obtido na concentração de $20,67 \mu \mathrm{M}$, enquanto que o percentual máximo de área cotiledonar $(66,11 \%)$, é observado na concentração de 34,80 $\mu \mathrm{M}$ (Figura 2).

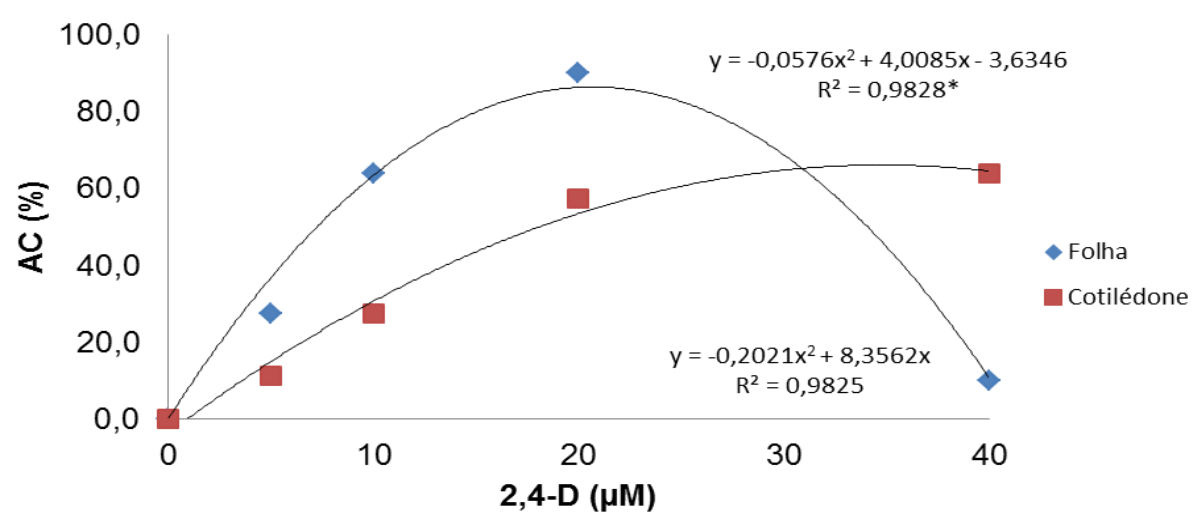

Figura 2- Porcentagem da área do explante recoberta por calos (AC\%) em A. cearensissubmetidos a diferentes concentrações de 2,4-D. *Significativo ao nível de $1 \%$ de probabilidade pelo teste F. Feira de Santana, 2016.

\section{CONCLUSÃO}

A auxina 2,4-D é eficiente para a formação de calos em segmentos foliares e cotiledonares de A. cearensis.

\section{REFERÊNCIAS BIBLIOGRÁFICAS}

AHUJA, M. R. Micropropagationofwoodyplants. London: Kluwer Academic Publishers, v. 41, 507 p. 1992.

ALMEIDA, J. R. G. S. et al. Amburana cearensis - uma revisão química e farmacológica. Scientia Plena, v. 6, n. 11, 2010.

BERTOZZO, F. \& MACHADO, I. S. Meios de Cultura no Desenvolvimento de ápices caulinares de mamoneira (Ricinuscommunis L.) in vitro. Ciência e Agrotecnologia, 34(6): 1477-1482. 2010.

CAMPOS ,V. C. A. Micropropagação de Amburana cearensis (ALLEMÃO) A. C. SMITH. Dissertação (mestrado em Recursos Genéticos Vegetais) - Universidade Estadual de Feira de Santana, p.102, 2009.

FERREIRA, D.F. Sisvar: a computerstatisticalanalysis system. Ciência e Agrotecnologia. v.35, n.6, p. 1039-1042, 2011.

GRATTAPAGLIA, D.; MACHADO, M.A. Micropropagação. In: TORRES, A.C.; CALDAS, L.S.; BUSO, J.A. (Orgs.). Cultura de Tecidos e Transformação Genética de Plantas. Brasília: Embrapa - SPI / Embrapa - CNPH. p.:183-260. 1998.

LORENZI, H. Árvores brasileiras: manual de identificação e cultivo de plantas arbóreas nativas do Brasil. Nova Odessa: Ed. Plantarium, 352p. 1992. 